\title{
Teacher Effectiveness by Enhancing the Self-Concept and Interpersonal Relations: Strategies and Techniques
}

\author{
Dr. Joyce E. Kyle Miller \\ Texas A\&M University-Commerce \\ USA
}

\begin{abstract}
The connection between teacher effectiveness, the self-concept and interpersonal relations is seldom reflected in research literature today. A search of selected databases reveals that there was a plethora of research and writings addressing this topic during the 60s and 70s. The purpose of this study is to report the results of an examination of forty-one publications predominantly from the 1970s which addressed techniques for enhancing the personal and interpersonal relations of preservice teachers. This study will examine this literature for answers to the following questions: What is the impact of teacher education programs on teacher attitudes toward self and others? What do teachers need in order to develop as fully functioning persons? What are the structured group experiences known to impact the self-concept and interpersonal relations?
\end{abstract}

Keywords: teacher effectiveness, self-concept, interpersonal relations, preservice teachers, teacher education

In recent years, there has been a growing awareness that content-learning alone may constitute insufficient preparation for effective teachers. In the school environment, the teacher has the major responsibility for helping students develop affective and cognitive skills. The effective teacher must be aware of the dual role of the teacher as a person and as a scholar (Erwin, 2010; Theelen et al., 2019; Theelen et al., 2020). According to Lohbeck, Hagenauer andFrenzel(2018), teachers are prepared cognitively, but they lack adequate personal and interpersonal skills. Teacher education programs need to blend affective and cognitive experiences in preparing today's effective teacher. However, Lohbeck, Hagenauer \& Frenzel (2018) found that “....research on teachers' self-concepts is largely missing, particularly, in terms of its structure and influence on desirable educational outcomes such as teachers' emotions related to teaching" (p. 111).In the mid-1960s, the United States Office of Education requested that teacher education institutions submit proposals for innovative programs for elementary pre-service teachers (Garvey, 1970). In less than four months, eighty proposals were submitted to the Office of Education. Many of these proposals included plans for empathy training, human relations, or sensitivity training (Garvey, 1970). During the 1960s and 1970s, educational institutions made progress toward increased humanization. Teacher education institutions reorganized departments and implemented courses based on the humanistic philosophy. Courses and workshops were organized to enhance the human relations skills of in-service and pre-service teachers (Garvey, 1970).

This article is a review of literature from 1951-1975 addressing the self-conceptand interpersonal relations of secondary education preservice teachers. A plethora of possible solutions embodied in concepts, programs and strategies resulted from this study. This literature review was delimited to EBSCO, Academic Search Complete, and Proquest Dissertations and Theses Full Text databases. Self-concept, Interpersonal Relations, Preservice Teachers, Teacher Education, and Secondary Education were the keywords used in conducting the literature search. Selected literature was delimited to publications which met one or more of the following criteria: publications between 1951 through 1975, full text, written in English. A selection of forty-one (41) publications wasincluded in the study. Thirty-three (33) or Eighty percent (80\%) of the publications were published between 1970 and 1975; Six (14\%) of the publications were published between 1962 and 1966. Two of the publications were published in 1951 and 1958 by Carl Rogers and William Schutz respectively and were considered seminal works on interpersonal behavior. Seventeen (41\%) of the publications were books; twelve (29\%) of the publications were journal articles; ten $(24 \%)$ of the publications were evenly divided as dissertations or conference paper presentations and two (5\%) monographs were included in the review. These publications were used to address the following research questions selected for this review: What is the impact of teacher education programs on teacher attitudes toward self and others? What do teachers need to develop as fully functioning persons? What are the structured group experiences known to impact the self-concept?

What is the impact of teacher education programs on teacher attitudes toward self and others?

Investigations by Couch (1970) and Murad (1975) revealed that teacher education programs usually do not prepare preservice teachers along personal dimensions which are basic to teacher effectiveness. 
Couch (1970) used the Tennessee Self-Concept Scale (TSCS) to collect pre-test and post-test data from pre-service teachers enrolled in three different phases of a teacher education program. Couch reported that no significant changes in the self-concept occurred from the beginning to the end of the undergraduate teacher education sequence. By the end of the teacher education block and student teaching, pre-service teachers' self-perceptions tended to be more stable. Murad (1975) also studied cross-sectional samples of three groups of pre-service teachers at different sequential points in a teacher education program. The investigator sought to determine if a teacher education program could affect preservice teacher's pupil control ideology, their attitudes of human relations, and their values of educational practice in a more conservative direction. Murad (1975) reported that there were differences in attitudes toward pupil control ideology and attitudes toward human relations of students entering the program and those completing the professional education sequence. Students enrolled in a teacher education program who were farthest along in the program were more conservative in pupil control ideology and human relations attitudes. These studies revealed that knowledge of subject matter alone may not be sufficient preparation for teachers who must prepare young people.

\section{What do teachers need to develop as fully functioning persons?}

Boy and Pine (1971) stated that teachers and students need "positive enabling experiences to develop fully as persons" (Boy \& Pine, p. 3). Because teaching is a personal expression of self, teachers need to work toward their potential as fully-functioning individuals (ASCD, 1962). Combs, et al. (1974) stated, "people learn that they are liked, wanted, acceptable, and able from experiences of having been treated that way by the people around them and from successful experiences that teach them they are able" (Combs, et al., p. 92).

The self-concept and interpersonal behavior are highly stable variables (Brownfain, 1965; Soares \& Soares, 1974). It has been shown that selected strategies and instructional techniques can be used to effect changes along these personal dimensions (DeMarte\&Sorgman, 1973; Lee, 1970; Levin \& Kurtz, 1974). It has been contended that since the selfconcept is formed through interaction with others, structured group experiences may be most effective in enhancing the self-concept and interpersonal relations (Appell \& Appell, 1965; Boy \& Pine, 1971; Combs, et al., 1974; Hipple, 1973).

In a correlational study by Lieberman, Yalom, and Miles (1973) and an experimental study by Levin and Kurtz (1974), it was shown that structured group experiences were favored by participants and produced desired results. Lieberman, Yalom, and Miles (1973) labeled the groups as high-exercise (structured) or low-exercise (non-structured) groups. The results of their study revealed that the participants favored the structured group. Reactions by the participants in the structured group indicated that their group was more cohesive and constructive. The participants felt that they learned more and perceived their group leader as more competent than the participants in the non-structured group.

The results of the Lieberman, Yalom, and Miles study (1973) were validated by Levin and Kurtz (1974) in an experimental study. Levin and Kurtz found that the participants in the structured groups reported higher levels of egoinvolvement in their groups, greater self-perceived personality changes, and greater perceived group unity than the participants in the non-structured groups. Structured group experiences are usually designed so that all group members are provided an opportunity to participate in group interaction, to experiment with new behaviors, and to share ideas with other group members. Such structuring ensures that group objectives will be attained and increases the possibility that personality variables will be affected (Levin \& Kurtz, 1974; Lieberman, Yalom\& Miles, 1973).

Padgett and Gazda (1968) investigated the effect of group guidance and group counseling procedures on the selfconcept and professional attitudes of pre-service teachers. The subjects were selected from an introductory education course at the University of Georgia. Pre-test and post-test measures were collected by means of the TSCS, the TERP Attitude Scale, and Vocational Decision Questionnaire. Participant-feedback was gathered by means of an Attitudinal Questionnaire. The experimental group participated in group guidance and group counseling experiences. The control group was exposed to a regular classroom experience only. Results revealed significant and directional changes for the group participants on measures of the TSCS. Significantly greater gains were reported for the experimental group on the Identity, Distribution, and Self-Criticism scores of the TSCS. Overall, the group guidance and counseling students tended to be more confident of their self-perceptions, more positive, and less defensive, as evidenced by higher SelfCriticism scores than the regular classroom group. The results of this study indicated that dimensions of the personality can be affected when the learner is personally involved in the learning process. The authors encouraged further research on the use of groups to facilitate personal development of pre-service teachers (Padgett \&Gazda, 1968).

Axelberd (1970) found that a twelve-hour growth group could effectself-concept change in thirty-nine participants. Comparative data were collected from a control group of twenty-one students who were enrolled in a mental hygiene course. Pre-test scores on the TSCS showed that the control group exhibited a higher positive self-concept than the growth group. However, post-test administration of the TSCS indicated that the experimental group had improved on an average of three times as much as the control group. 
The consistent improvement made by the experimental group attests to the legitimacy of the use of growth groups in enhancing self-perceptions. Self-growth in a group setting tends to be encouraged by several facilitating conditions. Appell and Appell (1965, p. 40) found that the "nonjudgmental," "nonthreatening," "accepting," group climate frees participants to be less defensive, more expressive, open, and trustful of the group. This type of atmosphere encourages sharing within the group. Participants come to value their own contributions and those of others regardless of how appropriate, agreeable, or divergent. As stated in the 1962 ASCD Yearbook, an individual is free to change his values only when he is free to hold them. When he is free to hold them, he is not forced to defend them. When he feels that his values are not condemned or categorized as "bad," he can then allow them to be explored (explored, not judged) by himself and by others. Out of exploration can come change and the development of new values based upon facts and upon new ways of seeing or perceiving $(1962$, p. 96).

A circle-seating arrangement provides for face-to-face communication and encourages listening to verbal and nonverbal communication cues. In addition to these facilitating conditions, participants should be free to choose to participate or not to participate in any phase of the group experience. Appell and Appell (1965, p. 40) have commented that "there are times when 'listening' participation can be especially meaningful to some. The absence of pressure permits each person to belong in the way appropriate for that person."Whenever possible, the source of group discussions should be the concerns and questions raised by individual students. Films and thought-provoking readings may be used to stimulate discussions which may lead to the exploration of ideas, attitudes, and feelings. Appell and Appell (1965) also recommended the use of resource persons, tape recordings, and role-playing exercises.

Gowan (1974) found that working within a group can serve as a powerful stimulus to self-concept change. By interacting in a group situation, participants may realize that their problems are not unique, that others share similar problems and have made similar mistakes in life. Gowan stated "Nothing does so much harm as to feel that we are uniquely bad and have a problem totally unlike anyone else's" (1974, p. 104). The group provides opportunities for problem-sharing and the sharing of solutions employed in resolving difficulties. The basis for a positive self-conceptis "objective feed-back from one's peers" (1974, p. 105). An individual who does have a negative self-attitude will strive to protect himself from feedback because of fear that this information will be negative. In a group situation, this individual can be helped to "emerge from social isolation" (1974, p. 105) and aided in viewing himself as others see him. In a facilitative group environment, group members are able to help each other to feel that they are good, worthy, capable, and valued as human beings.

\section{What are the structured group experiences known to enhance the Self-concept?}

Values clarification, problem solving, roleplaying, transactional analysis, and human relations training are approaches and techniques which historically have been used individually and in combination to enhance the self-concept (Raths, Harmin\& Simon, 1966). These strategies are designed to be used by groups or individuals and are based on criteria for self-concept enhancement. The values clarification strategy has been used effectively to help individuals discover themselves and what they value. The approach deals with the process of (1) choosing freely from alternatives after thoughtful consideration of the consequences of each alternative; (2) cherishing, being happy with the choice, willing to affirm the choice publicly; and (3) doing something with the choice repeatedly in some pattern of life (Raths, Harmin \& Simon, 1966, p. 30). Collectively, this process is called valuing.

The characteristics of one who does have a clear set of values closely parallel the traits of an effective teacher. Raths, Harmin, and Simon (1966) found that the individual who possesses a clear system of values is "more purposeful, more enthusiastic, more positive, and more aware of what is worth striving for" (Raths, et al., p. 4). He is reasonable consistent in his daily life and "relates to the forces and events and persons around him with considerable verve, purpose, and pride" (Raths \& et al., p. 4). The person who is not clear concerning his relationship with others seems to be personally confused and insecure. He is only able to cope with daily living because he has "learned a pattern of behavior that compensates for his not knowing how to deal with the dynamics of the surrounding world" (Rath\& et al., p. 6).Simon and deSherbinin (1975) and Wilgoren (1973) have found that the group strategies employed in values clarification provide for interpersonal sharing and are effective for enhancing the self-concept. Simon and deSherbinin (1975) stated that one of the specific aims of values clarification is to help people improve their relations with each other. When people know what they want, believe strongly, and are able to follow up on commitments, they are nicer people to have around. You can count on them. And, indeed, when conflict arises, they know how to work through conflict to reach resolution. Because they are purposeful and creative, they're better able to share and give warmly and consistently of themselves (Simon \& DeSherbinin, p. 681).Findings by Wilgoren (1973) revealed that the self-concept of pre-service teachers can be influenced by values clarification strategies. The purpose of Wilgoren's study was to compare the effects of values clarification strategies by Simon and Oliver on the self-concept. Results indicated that students receiving either the Simon or the Oliver values clarification treatment evidenced improved self-concepts. 
Transactional analysis is also a method which is "concerned with discovering and fostering awareness, selfresponsibility, and genuineness" (James \& Jongeward, 1971, p. ix). The ultimate objective of transactional analysis is to help individuals direct and gain control of their environment. Transactional analysis is basically a group approach. James and Jongeward (1971) stated that "the group serves as a setting in which people can become more aware of themselves, the structure of their individual personality, how they transact with others, the games they play, and the scripts they act out" (James \& Jongeward, p. 11).Transactional analysis is based on the concept of confluence. Experiences which focus on both the affective and intellectual components of the personality are used (Berne, 1964). The self-concept is enhanced as a result of gaining knowledge of the various "selves" and using this knowledge to facilitate interactions with others. As with the values clarification approach, individuals develop positive self perceptions as a result of feeling in control of their environment.

Tallon Brown (1973) examined the effect of transactional analysis on positive self-concept change. The treatment consisted of nineteen sessions of transactional analysis group therapy over a period of eight months. Selfunderstanding was the major objective of the group activities. The TSCS was used to measure changes in the selfconcept. Significant differences were found between the experimental and the control groups on measures of Self Esteem and Self Satisfaction. Further examination of the TSCS profile sheet revealed that the transactional analysis group made improvements on each of the nine scales from the TSCS. Roleplaying and problem solving techniques may be used with either values clarification or transactional analysis approaches. These approaches and techniques may be used in combination. Roleplaying and problem solving are most effectively used in group situations where participants give and receive feedback and share ideas. Both of these techniques facilitate personality improvement. Problem solving is most effective when an orderly sequence of steps is followed which results in a solution to a problem. Problem solving approaches are usually elaborate and systematic. Phillips and Erickson (Phillips \& Erickson, 1970) have proposed that a less structured problem solving model may be more desirable when the objective is appreciation and understanding of self and others. Phillips and Erickson commented that when the focus is on the individual, examination of one's personal behavior, or on helping individuals better understand a problem, the process might be described as the use of a problem solving model to share ideas. The authors stated that "the problem the group is really attacking is the sharing of ideas and the heightening of perceptions, both of which are individual matters" (Phillips \& Erickson, 1970, pp. 12-13). It was suggested that a problem solving model which includes identifying the problem or problems, generating multiple solutions, selecting the best solution to the problem is sufficient to generate group interaction.

In a study by Gross and Schwebel (1974), it was shown that the effective problem solver is reflective. He has confidence in himself and his abilities and maintains adequate interpersonal relations. Gross and Schwebel (1974) used the Personal Orientation Inventory (POI) to evaluate the effect of a problem solving approach used in an undergraduate psychology course. Pre-test and post-test measures were collected on the ninety-six (96) students enrolled in a ten-week course. The experimental group made significant improvements in Inner Directedness, Existentiality, Spontaneity, Self-Acceptance, Synergy, and the Capacity or Intimate Contact. Problem solving is an effective technique in changing perceptions of self and others. It "...requires that personal feelings, attitudes, ideas, questions and concerns be brought to light and examined openly" (Boy \& Pine, 1971, p. 116).

Roleplaying is a technique which has been referred to as "an important value-eliciting strategy" (Raths, Harmin\& Simon, 1966, p. 121). Roleplaying allows one to assume a new identity for a limited period of time in a protected environment (Curwin \& Fuhrmann, 1975). According to Rath, Harmin and Simon (1966), the technique has the effect of causing real feelings and values to surface. The post roleplay allows the participants and observers an opportunity to explore the effect of values, attitudes, and beliefs on behaviors. Roleplaying can change attitudes, contribute to behavioral changes, and enhance learning (Chesler \& Fox, 1975; Gergen, 1971). Roleplaying also has the effect of narrowing the gap between knowing and doing which is a problem faced by beginning teachers (Kenworthy, 1973). Kenworthy observed, Many prospective and in-service teachers...gain a better understanding of themselves through role-playing and the subsequent analysis, in class or in private conferences, of the socio-dramas in which they have taken part. Often they gain security through successful experiences the first time they play a role, or through reenactment of a role after their initial failure has been discussed by their peers. Very often they learn to anticipate difficulties they will encounter in their own classes. Frequently they discover their own fears and short-comings and begin to work on them (p. 243). Kenworthy (1973), Chesler and Fox (1975) found that roleplay can add variety to a classroom which can have the effect of enhancing teaching and learning. The use of role-playing in teacher education provides pre-service teachers with knowledge of roleplay as an instructional technique. The use of roleplay also can lead to discussions of how the role of the teacher is affected by the use of different instructional strategies. Kenworthy (1973), Chesler and Fox (1975) have found that satisfactory use of role-playing best proceeds in a classroom climate which is characterized by frankness, openness, and genuine acceptance. 
The problem selected for roleplay may be based on real-life situations (Chesler\& Fox, 1975). It was recommended that the role-play situation be realistic enough for students to see its relevance to their future roles as teachers (Chesler\& Fox, 1975). The problem situation selected should be challenging but not too complex for the ability of the students. According to Chesler and Fox (1975), the problem selected should be one which "can be handled, solved, or investigated by the group members without making them feel inadequate" (p. 426).

Gottlieb (1973) found that the use of a combination of experiences such as values clarification, transactional analysis, problem solving, and roleplaying can have the effect of enhancing perceptions of self and others. Gottlieb conducted two different investigations in an effort to test the effect of two approaches on self-concept change. The TSCS was used to measure the effect of the treatment. The results indicated that the use of only one kind of activity as the treatment variable seldom produced the hypothesized results. Gottlieb (1973) surmised that the variety provided by using several experiences may be effective in enhancing the self-concept and interpersonal relations.

During the 1960s and 1970s, human relations training became a broad, descriptive term for group experiences designed to help participants understand themselves and others. Human relations training have been broadly applied to include group experiences which include objectives for interpersonal development, personal development, and intergroup development. Human relations training is based on the use of experiences which encourage self-discovery and was viewed by Appell and Appell (1965) and Hipple (1973) as a natural strategy for enhancing perceptions of self and others. Rinne (1974) suggested six criteria which he believed should be considered in designing effective human relations curriculum materials. Rinne believed that effective human relations training should cause people to change. The human relations experiences should involve the participant in an activity which allows experience of the consequence of behavior. The participants should be able to apply the group experiences to daily interactions with others. In order to develop confidence in the performance of skills, the human relations program should provide for duplication of any activity. Activities which may be repeated allow participants to practice skills and to teach these skills to others.

Rinne (1974) believed that a successful human relations program designed for classroom use should include ways to protect the participants from potentially harmful situations. He recommended that confrontation be avoided when the purpose is to involve group members in "mild forms of interaction skills development" (Rinne, 1974, p. 39). Rinne stressed those effective human relations materials should include an option to participate, not to participate, or to withdraw from participation at any stage of an activity.

\section{Conclusions}

What are the take-a-ways from this historical review of the self-concept and interpersonal relations and the connection to teacher effectiveness?

1. There is a relationship between the self-concept and interpersonal relations.

2. Rogers (1951), Schutz (1958), and Goble (1970) have theorized that human beings have personal needs which can only be satisfied in interpersonal relationships.

3. An individual's self-concept develops through interactions with significant others (Diggory, 1966; Epstein, 1973; Gergen, 1971; Swensen, 1973).

4. The adequacy of one's self-concept is determined by the quality of his relations with others, how he acts toward others and how others act toward him (Combs et al., 1974; Gergen, 1971).

5. The relationship is highly interrelated. Studies by Thompson (1972) and Richmond, Mason, and Padgett (1972) are two of the few empirical investigations of the self-other relationship. These correlational studies support the theory that the self-concept is related to interpersonal relations.

6. The self-concept and interpersonal relations are highly stable variables (Brownfain, 1965; Diggory, 1966; Gergen, 1971; Gottlieb, 1973). However, research has shown that there are specific strategies and techniques which contribute to enhancing the self-concept and interpersonal relations:

7. The structured group experience is the most successful approach for enhancing the self-concept and interpersonal relations (Combs et al., 1974; Green, 1970; Levin \& Kurtz, 1974; Lieberman, Yalom\& Miles, 1973).

8. Self-growth in a group setting is facilitated by a nonjudgmental, nonthreatening atmosphere of total acceptance (Appell\&Appell, 1965; ASCD, 1962; Gowan, 1974; Rogers, 1951).

9. A circle-seating arrangement encourages face-to-face communication (Boy \& Pine, 1971; Gowan, 1974; James \&Jongeward, 1971).

10. Participants should always have the option of choosing to participate, choosing not to participate, or choosing to withdraw from an activity at any stage of involvement (Appell\&Appell, 1965; Gowan, 1974; Rinne, 1974). 
11. Whenever possible, the topic of discussion should emerge from the group (Appell\&Appell, 1965; Gowan, 1974).

12. Values clarification and transactional analysis are group strategies which will help group members gain control over their behavior and environment and will contribute to an enhancement of the self-concept and interpersonal relations (Berne, 1964; Brown, 1973; Simon, Howe \& Kirschenbaum, 1972; Simon \&deSherbinin, 1975; Wilgoren, 1973).

13. Roleplaying and problem solving techniques are effectively used in group situations to stimulate group interaction and the interchange of ideas among group participants (deSherbinin, 1975).

14. Roleplaying and problem solving may be effectively used to enhance the self-concept and interpersonal relations (Chesler\& Fox, 1975; Curwin\&Fuhrmann, 1975; Gergen, 1971; Gross \&Schwebel, 1974; Phillips \& Erickson, 1970; Raths et al., 1966).

15. An integrated approach which combines the use of several different strategies is superior to any single approach (Borke\& Burstyn, 1970; Calliotte, 1971; Gottlieb, 1973). The most effective experiences provide for cognitive and experiential learning.

16. The group activities should help a group member learn interpersonal skills which may be used in daily interactions with individuals outside of the group (Rinne, 1974).

The integrative approach does seem to be a viable means of helping pre-service teachers become involved in a variety of experiences designed to effect the affective and cognitive domains. It is possible that such a variety of cognitive and affective experiences may assist in preparing the effective teacher needed today.The self-concept has been shown to be an important variable underlying an individual's behavior. It also has been shown that there is a relationship between interpersonal relations and the self-concept. There is a need for the integration of self-concept and interpersonal relations activities into existing teacher education courses. There is also a need for testing and comparing the effectiveness of traditional methods of teaching education courses with experimental approaches to teaching the same courses. The theory of perceptual psychology is based on the belief that human behavior is determined by an individual's perceptions. Whether a teacher is an effective teacher or not depends largely on his self-concept. According to Combs, of all the perceptions existing for an individual none are so important as those he has about himself. The individual's self is the center of his world, the point of origin for all behavior. What he believes about himself affects every aspect of his life (11, p. 14).

\section{References}

Appell, C., \& Appell, M. (1965). More tender hearts: An appeal for teacher sensitivity. Teacher's College Journal, $11(11), 39-41$.

Association for Supervision and Curriculum Development. (1962). Perceiving, behaving, becoming, Yearbook of the Association for Supervision and Curriculum Development. Washington, DC: National Education Association.

Axelberd, F. J. (1970, March). Effects of growth groups on the self-concept as measured by the association convention. Paper presented at the American Personnel and Guidance Association, New Orleans, Louisiana.

Berne, E. (1964). Games people play. New York, N. Y.: Ballantine Books.

Borke, H., \& Burstyn, J. W. (1970). The new teacher and interpersonal relations in the classroom. Journal of Teacher Education, 21, 378-381.

Boy, A. V., \& Pine, G. J. (1971). Expanding the self: personal growth for teachers. Debuque, Iowa: Wm. C. Brown.

Brown, T. H. (1973). Change of self-concept with an intact group by a transactional analysis approach (Unpublished doctoral dissertation). Southern Illinois University, Carbondate, Illinois.

Brownfain, J. J. (1965). Stability of the self-concept as a dimension of personality. In D. Hamachek (Ed.), The self in growth: Teaching and learning (pp. 269-287). Englewood Cliffs, New Jersey: Author.

Calliotte, J. A. (1971). Initial attempts at developing appropriate human relations experiences for potential teachers. Paper presented at the American Personnel and Guidance Association, Atlantic City, N. J.

Chesler, M., \& Fox, R. (1975). Role playing in the classroom. In D. A. Read \& S. Simon, Humanistic education sourcebook. Englewood Cliffs, NJ: Prentice-Hall.

Combs, A. W., et al. (1974). The professional education of teachers. Boston, MA: Allyn and Bacon.

Couch, J. D. (1970). Prospective high school teachers' self-concept as reflected by the Tennessee Self-Concept Scale (Unpublished doctoral dissertation). University of Arkansas, Fayetteville, Arkansas.

Curwin, R. L., \& Fuhrmann, B. (1975). Discovering your teaching self: Humanistic approaches to effective teaching. Englewood Cliffs, New Jersey: Prentice-Hall.

DeMarte, P. J., \& Sorgman, M. I. (1973, November). A pilot to investigate effects of courses in humanistic education on self perceptions of pre-service teacher's. Paper presented at the National Council for the Social Studies, San Francisco, California. 
Diggory, J. (1966). Self-evaluation: Concepts and studies. New York, NY: John Wiley and Sons.

Epstein, S. (1973). The self-concept revisited or a theory of a theory. American Psychologist, 28, 404-416.

Erwin, J. (2010). Inspiring the Best in Students. Alexander. VA. ASCD.

Garvey, R. (1970). Self-concept and success in student teaching. Journal of Teacher Education. 21. 357-361.

Gergen, K. (1971). The concept of self. New York, NY: Holt, Rinehard and Winston.

Goble, F. G. (1970). The third force: The psychology of Abraham Maslow. New York, NY: Grossman.

Gottlieb, M. R. (1973, April). The effects of laboratory training methods on highly stable variables such as self esteem and self-disclosure. Paper presented at the International Communication Association, Montreal, Canada.

Gowan, J. C. (1974). Effecting change in the self-concept. Journal of the National Association of Women Deans, Administrators, and Counselors, 33, 103-106.

Green, J. G. (1970). A study of expressed behavior changes occurring as a result of exposure to filmed classroom situations and T-Group sensitivity training (Unpublished doctoral dissertation). Washington State University, Seattle, Washington.

Gross, S. J., \&Schwebel, A. I. (1974, October, 1974). Evaluation with the personal orientation inventory of a problemsolving approach in teaching an undergraduate psychology course. Psychological Reports, 33, 623-626.

Hipple, J. L. (1973). Personal growth outcomes due to human relations training experiences. Journal of College Student Personnel, 14, 156-164.

James, M., \& Jongeward, D. (1971). Born to win: Transactional analysis with gestalt experiments. Reading, Massachusetts: Addison-Wesley .

Kenworthy, L. S. (1973). Role-playing in teacher education. The Social Studies, 64, 243-246.

Lee, W. S. (1970). Human relations training for teachers: The effectiveness of sensitivity training. California Journal of Educational Research, 21, 28-34.

Levin, E. M., \& Kurtz, R. R. (1974). Structured and nonstructured human relations training. Journal of Counseling Psychology, 21, 526-531.

Lieberman, M. A., Yalom, I. D., \& Miles, M. B. (1973). Encounter groups: First facts. New York, NY: Basic Books.

Lohbeck, A., Hagenauer, G., Frenzel, A. (2018). Teachers' self-concepts and emotions: Conceptualization and relations. Teaching and Teacher Education. 70, 111-120.

Murad, B. J. (1975). A study of the effects of teacher education program on dimensions of teacher treainees (Unpublished doctoral dissertation). University of Kentucky, Lexington, Kentucky.

Padgett, H., \& Gazda, G. (1968). Effects of Group Guidance and Group Counseling on the Self Concept and Professional Attitudes of Prospective Teachers. Journal of the Student Personnel Association for Teacher Education, 6, 42-49.

Phillips, G. M., \& Erickson, E. C. (1970). Interpersonal dynamics in the small group. New York, NY: Random House.

Raths, L. E., Harmin, M., \& Simon, S. B. (1966). Values and teaching. Columbus, Ohio: Charles E. Merrill .

Richmond, B. O., Mason, Jr., R. L., \& Padgett, H. (1972). Self-concept and perceptions of others. Journal of Humanistic Psychology, 12, 103-111.

Rinne, C. H. (1974). Criteria for evaluating curriculum materials in human relations. Educational Leadership, 32, 3740.

Rogers, C. R. (1951). Client-Centered Therapy. Boston, MA: Hougthton Mifflin.

Schutz, W. C. (1958). FIRO: A three-dimensional theory of interpersonal behavior. New York, NY: Rinehart and Company.

Simon, S., \& DeSherbinin, P. (1975). Values clarification: It can start gently and grow deep. Phi Delta Kappan, 56, 679-683.

Simon, S., Howe, L. W., \& Kirschenbaum, H. (1972). Values clarification: A handbook of practical strategies for teachers and students. New York, NY: Hart.

Soares, A. T., \& Soares, L. M. (1974, April). Self-perceptions as affective dimensions of student teaching. Paper presented at the American Educational Research Association, Chicago, Illinois.

Swensen, Jr, C. (1973). Introduction to Interpersonal Relations. Glenview, Illinois: Scott, Foreman .

Theelen, H., Beemt, v. d., A., \& Brok, d., P. (2019). Classroom simulations in teacher education to support preservice teachers' interpersonal competence: A systematic literature review. Computers and Education, 129, 14-26.

Theelen, H., Beemt, v. d., A., \& Brok, P. d. (2020). Developing preservice teachers' interpersonal knowledge with 360degree videos in teacher education. Teaching and Teacher Education, 89.

Thompson, W. (1972). Correlates of the Self-concept, Research Monograph No.6. Nashville, Tennessee: The Dede Wallace Center.

Wilgoren, R. A. (1973). The relationship between the self-concept of pre-service teachers and two methods of teaching values clarification (Unpublished doctoral dissertation). University of Massachusetts, Amherst, MA. 